\title{
Website E-Commerce sebagai Media Promosi Penjualan Pengolahan Hasil Laut Kelompok Istri- Istri Nelayan di Karangantu
}

\author{
Novi Sofia Fitriasari ${ }^{1}$, Ayang Armelita Rosalia ${ }^{2}$, Luthfi Anzani ${ }^{3}$, \\ Della Ayu Lestari ${ }^{3}, K_{\text {Kuk Widiyanto }}^{3}$, Wildan Aprizal Arifin ${ }^{3}$, Denta Tirtana ${ }^{4}$, \\ Fawaz $^{3}$, Cakra Rahardjo ${ }^{3}$ \\ 1, 2, 3 Universitas Pendidikan Indonesia, Indonesia \\ ${ }^{4}$ Institut Pertanian Bogor, Indonesia
}

\begin{tabular}{|c|c|c|}
\hline \multicolumn{3}{|c|}{ A B S T R } \\
\hline \multicolumn{3}{|c|}{$\begin{array}{l}\text { E-COMMERCE WEBSITE AS A MEDIA FOR PROMOTING SALES OF FISHERMEN'S } \\
\text { WIFE GROUP SEAFOOD PROCESSING IN KARANGANTU. Currently fish caught from } \\
\text { husbands who work as fishermen can only be marketed fresh, and if they are not sold, they } \\
\text { will be discarded or used as animal feed. Fish product development processing is being } \\
\text { carried out by agencies for groups of fishermen's wives. We carried out community service } \\
\text { by marketing team that can help increase fishermen household income. Marketing strategy } \\
\text { is by creating a website. The objectives of community service through this activity are as } \\
\text { follows: (a) Introducing fishermen's wives to information media for sales, (b) Creating } \\
\text { Banten Bahari E-Commerce Website (BAHARI) which later can be used as marketing } \\
\text { media by fisherman wives. Method to achieve the first goal is by community education, } \\
\text { and for online we use the Waterfall method. The socialization of online media introduction } \\
\text { for marketing marine products in Karangantu was well responded by fishermen's wives. } \\
\text { Making the BAHARI website is one of promotional media that fishermen's wives can use } \\
\text { in the future. }\end{array}$} \\
\hline ords: & Product, Fisherma & terfall Method. \\
\hline & & \\
\hline
\end{tabular}

Suggested citation:

Fitriasari, N. S., Rosalia, A. A., Anzani, L., Lestari, D. A., Widiyanto, K., Arifin, W. A., Tirtana, D., Fawaz, \& Rahardjo, C. (2020). Website e-commerce sebagai media promosi penjualan pengolahan hasil laut kelompok istri-istri nelayan di Karangantu. Jurnal Pengabdian Pada Masyarakat, 5(4), $927-$ 934. https://doi.org/10.30653/002.202054.669

Open Access I URL: http://ppm.ejournal.id/index.php/pengabdian/article/view/669

${ }^{2}$ Corresponding Author: Program Studi Sistem Informasi Keluatan, Universitas Pendidikan Indonesia Kampus Serang; Jl. Ciracas No.38, Serang, Kota Serang, Banten, Indonesia. Email: ayang.armelita@upi.edu 


\section{PENDAHULUAN}

Kampung Karangantu Kelurahan Banten merupakan wilayah yang memiliki potensi sumberdaya kelautan yang tinggi. Terdapat Pelabuhan Perikanan Nusantara (PPN) Karangantu di wilayah tersebut yang akan menjadi faktor pendukung pengembangan wilayah. Ketika musim ikan terjadi banyak ikan yang kurang termanfaatkan dan ketika paceklik nelayan tidak dapat penghasilan. Saat ini istri-istri nelayan hanya menunggu suami nya melaut dan setelah itu membantu menjual ikan segar ke pengumpul ikan dan ke pasar ikan. tetapi pendapatan rumah tangga nelayan rata-rata masih kurang. Sehingga kami ingin membantu untuk meningkatkan pendapatan keluarga nelayan agar kontinyu sepanjang tahun, dengan melatih istri-istri nelayan untuk memasarkan produk olahan ikan secara daring.

Memperkenalkan teknologi-teknologi terutama teknologi pemasaran daring dalam bidang peningkatan ekonomi masyarakat perikanan di Karangantu. Salah satu yang dapat digunakan adalah media sosial sebagai media promosi pariwisata oleh millenials (Chotijah 2020). Sebagai bentuk kepedulian dan implementasi ilmu yang diperoleh dan dikembangkan. Kegiatan-kegiatan yang akan dilakukan dalam pengabdian ini berupa pemberdayaan sumberdaya manusia khususnya untuk kaum wanita pesisir dalam program peningkatan ekonomi melalui usaha kecil daring dengan cara memperkenalkan segala bentuk teknologi daring yang membantu menyebarluaskan maupun mempromosikan produk-produk yang di produksi oleh kaum wanita di daerah tersebut. Dimulai dengan perkenalan awal apa itu teknologi dan apa fungsi teknologi tersebut kepada masyarakat.

Indonesia merupakan salah satu negara di dunia yang memiliki perairan tropis sangat luas dan kaya akan sumberdaya kelautan dan perikanan yang beragam. Kebersihan laut menjadi salah satu hal yang berdampak bagi kehidupan selanjutnya. Laut juga menjadi salah satu investasi yang keindahannya bisa dinikmati dan dapat mensejahterakan masyarakat sekitar. Kekayaan alam Indonesia tidak dimanfaatkan dengan baik dengan alasan kurangnya edukasi dan pendidikan kelautan di Indonesia. Kelurahan Banten, Kota Serang merupakan desa yang mempunyai potensi sumberdaya keluatan yang unggul namun belum termanfaatkan dengan baik. Sebagian besar mata pencaharian warga Desa Karangantu yaitu sebagai nelayan kecil.

Era milenial sekarang, teknologi informasi selalu digunakan di berbagai bidang kehidupan. Terutama pada aspek kehidupan dalam bidang peningkatan ekonomi untuk mempermudah proses promosi. Teknologi sekarang juga dapat menjangkau kawasan yang luas untuk menyebarluaskan hasil-hasil produksi yang dihasilkan. Salah satu teknologi informasi yang dapat mengakses data dan informasi secara cepat, membutuhkan biaya murah dan tanpa ada batasan jarak adalah situs website (Parasaorantua, Pasoreh, \& Rondonuwu. 2017)

Pemerintah telah melakukan usaha-usaha untuk meningkatkan kompetensi SDM di bidang teknologi tersebut. Namun masih banyak masyarakat yang belum bisa dan belum memahami penggunaan teknologi tersebut, khususnya masyarakat-masyarakat yang tinggal di daerah pesisir seperti masyarakat yang tinggal di daerah Pelabuhan Perikanan Nusantara Karangantu, mereka membutuhkan bantuan untuk dapat menggunakan teknologi informasi. 
Masalah di kelompok masyarakat Pelabuhan Perikanan Nusantara Karangantu ini adalah masih minimnya pendidikan di masyarakatnya. Sumberdaya manusianya yang belum di berdayakan seluruhnya terutama istri-istri yang berada di sekitar Pelabuhan Perikanan Nusantara Karangantu tersebut. Solusi untuk permasalahan ini adalah meningkatkan pengetahuan dan keahlian melalui pelatihan promosi usaha kecil secara daring.

Sumberdaya laut yang didapatkan nelayan berupa ikan hasil tangkapan. Ikan yang didapatkan mayoritas berupa ikan segar. Pemasaran yang dilakukan biasanya nelayan

langsung menjual ke pengepul atau ke tempat pelelangan ikan. Terdapat beberapa ikan yang memiliki nilai eknomis rendah dalam bentuk segar sering terabaikan. Ikan tersebut biasanya dimanfaatkan sendiri sebagai lauk, dijadikan pakan ternak atau bahkan dijual. Saat ini sedang dilakukan pelatihan pembuatan pengolahan ikan oleh instansi pemerintah di wilayah tersebut.

Permasalahan selanjutnya yang terjadi yaitu bagaimana pemasaran hasil olahan ikan yang telah dilakukan istri-istri nelayan. Perkembangan teknologi yang saat ini muncul sangat pesat. Istri-istri nelayan di kampung Karangantu telah memiliki ponsel yang canggih. Namun pemanfaatannya masih hanya sekedar komunikasi dengan keluarga. Untuk memanfaatkan teknologi ini, maka kita akan melakukan pemasaran hasil olahan berbasis web. Website merupakan salah satu bentuk media promosi yang dapat mengembangkan potensi desa yang dimiliki (Hutaglung, Hermawan, \& Mulyana 2020).

Saat ini ikan hasil tangkapan dari para suami yang bekerja sebagai nelayan hanya dapat dipasarkan yang segar saja dan jika tidak terjual maka akan dibuang atau dijadikan pakan ternak. Pengembangan produk berupa pengolahan ikan sedang dilakukan oleh instansi lain untuk kelompok istri-istri nelayan. Pengabdian kepada masyarakat yang dilakukan adalah menjadi tim pemasaran yang dapat membantu meningkatkan pengahasilan rumah tangga nelayan. Pemasaran yang akan dilakukan adalah membuat website. Keberadaan website dapat dimanfaatkan untuk mempromosikan potensi yang dimiliki oleh setiap desa secara luas (Mansur, \& Kasmawi 2017).

Tujuan dilakukan pengabdian kepada masyarakat melalui kegiatan ini adalah sebagai berikut: (a) Memperkenalkan kepada istri-istri nelayan tentang media informasi untuk penjualan, (b) Membuatkan Website E-Commerce Banten Bahari (BAHARI) yang nantinya dapat dijadikan media pemasaran oleh istri-istri nelayan.

\section{METODE}

Lokasi pengabdian kepada masyarakat berada di sekitar wilayah Pelabuhan Perikanan Nusantara Karangantu, Kelurahan Banten, Kecamatan Kasemen, Kota Serang. Kelurahan Banten memiliki luas wilayah 5,7 km², merupakan wilayah pesisir yang berada di Provinsi Banten (BPS 2019). Mayoritas warga merupakan nelayan penangkap ikan, penjual dan pemasaran ikan. Sasaran utama adalah istri-istri yang merupakan istri nelayan dan pedagang atau pengepul ikan.

Pengabdian kepada masyarakat dengan tema memperkenalkan kepada istri-istri nelayan tentang media informasi untuk penjualan dilaksanakan padat tanggal 20 Desember 2019 yang bertempat di Aula Pelabuhan Perikanan Nusantara Karangantu. 
Metode yang dipakai dalam upaya mencapai tujuan yaitu metode pendidikan masyarakat. Materi yang disampaikan berjudul "Meningkatkan Minat Pasar Melalui Pengenalan Produk Secara Online untuk Kelompok Istri Nelayan di Karangantu". Kegiatan Pengabdian ini dihadiri oleh 50 orang istri-istri nelayan.

Pembuatan Website E-Commerce Banten Bahari (BAHARI) yang nantinya dapat dijadikan media pemasaran oleh istri-istri nelayan. Pembuatan website menggunakan metode Waterfall. Metode Waterfall adalah suatu proses pengembangan perangkat lunak berurutan, dimana kemajuan dipandang sebagai terus mengalir ke bawah (seperti air terjun) melewati fase-fase perencanaan, pemodelan, implementasi (konstruksi), dan pengujian (Tristianto 2018). Website dibangun berbasis web dengan menggunakan framework Codeigniter 3 dalam bahasa pemrograman PHP.

\section{HASIL DAN PEMBAHASAN}

\section{Memperkenalkan kepada istri-istri nelayan tentang media informasi untuk penjualan}

Tim dosen bersama mahasiswa Program Studi Sistem Informasi Kelautan telah melakukan survei ke Pelabuhan Perikanan Karangantu dan melakukan sosialisasi untuk meningkatkan pendapatan rumah tangga nelayan dengan pemasaran produk olahan ikan secara online untuk istri-istri nelayan, yang bertempat di balai pertemuan nelayan Pelabuhan Perikanan Nusantara Karangantu. Istri-istri nelayan dapat membantu perekonomian keluarga bahkan meningkatkan kesejahteraan suatu desa. Menurut Mukhlis, M., \& Yulianto, Y. (2020) Kelompok Wanita Tani (KWT) di Lampung Tengah dapat mendorong masyarakat untuk menjadikan kampung sebagai sentra perikanan dan produk olahannya sebagai produk unggulan/kekhasan daerah. Berikut dokumentasi pengabdian kepada masyarakat tahap awal yang telah dilakukan.

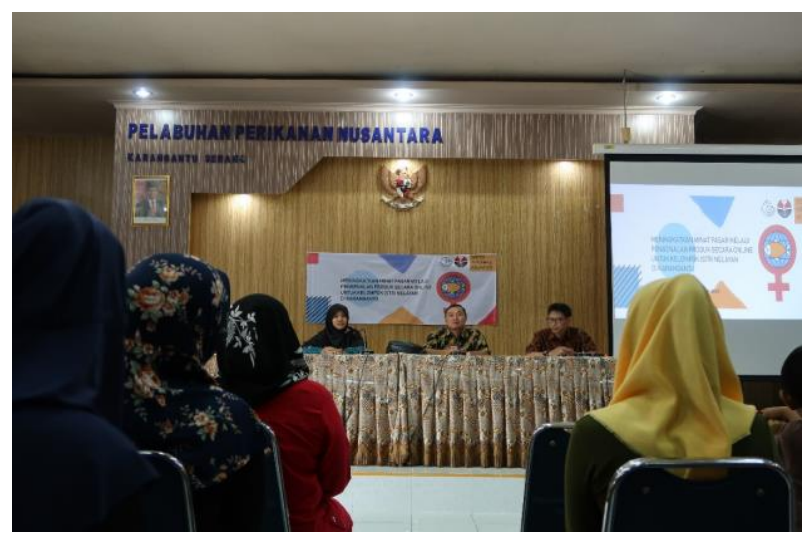

Gambar 1. Pembukaaan kegiatan osialisasi pengenalan media promosi daring 


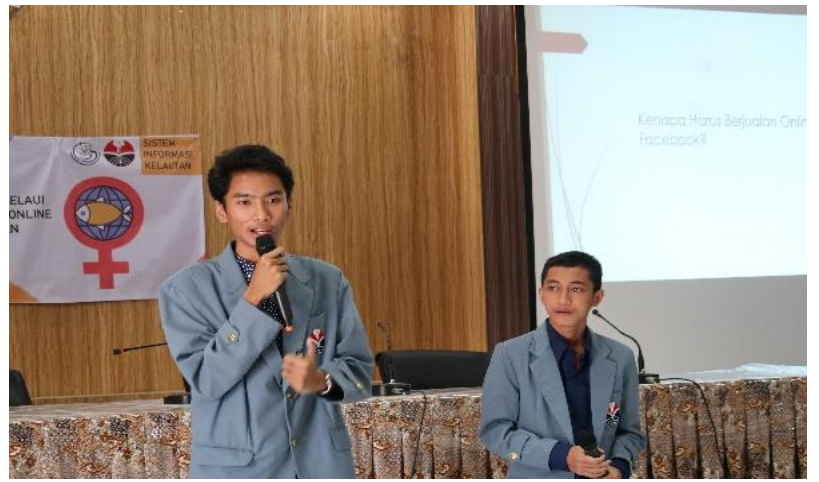

Gambar 2. Penyampaian materi

Sosialisai dilakukan untuk mendorong istri-istri melakukan olahan hasil perikanan baik berupa makanan atau berupa kerajinan tangan. Kegiatan juga didorong untuk menciptakan kelompok istri-istri yang memiliki antusias membuat kerajinan dan mengolah kreativitas dari hasil laut untuk meningkatkan ekonomi, meningkatkan penghasilan masyarakat setempat, dan meningkatkan kesejahteraan masyarakat. Dukungan dari berbagai institusi perlu dilakukan agar kesejahteran masyarakat desa meningkat melalui penguatan nilai produk (Majdi, M. Z., Rizkiwati, B. Y., \& Wirasasmita, R. H. (2020). Secara umum istri-istri nelayan antusias atas pelatihan yang diberikan. Terdapat beberapa kekhawatiran yang ditemui masyarakat untuk memulainya yaitu sumberdaya teknologi informasi yang kurang dikuasai, adaptasi terhadap sistem pemasaran yang ada dan takutnya terjadi hal yang tidak diinginkan seperti penipuan. Pemahaman tentang pentingnya literasi dengan menggunakan teknologi ataupun media perlu dilakukan agar penggunaan teknologi tepat guna (Meliyawati., Rohimajaya, N. A., Purlilaiceu., \& Trisnawati. (2020).

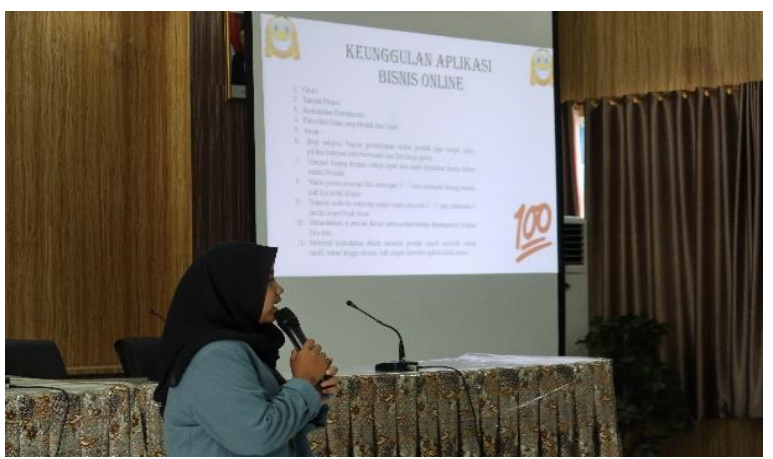

Gambar 3. Sesi diskusi

Membuatkan Website E-Commerce Banten Bahari (BAHARI) yang nantinya dapat dijadikan media pemasaran oleh istri-istri nelayan

Salah satu bentuk perkembangan teknologi dibidang perdagangan yaitu munculnya transaksi yang menggunakan media internet untuk menghubungkan antara produsen dan konsumen. Transaksi penggunaan teknologi internet merupakan kebutuhan bagi banyak orang karena dengan internet kita bisa mengakses dan menemukan segala informasi di seluruh dunia dengan cepat dan mudah. Situs web (website) sistem basis 
data produksi ikan dapat diakses melalui penjelajah web (web browser) seperti Google Chrome, Firefox, Internet Explorer, Opera, dan lainnya sehingga memudahkan siapapun untuk menggunakannya (Santausa, Mustaruddin, \& Simbolan 2020).

Pembuatan website ditujukan untuk kelompok masyarakat istri-istri nelayan yang berada di sekitar Pelabuhan Perikanan Nusantara Karangantu. Pada tahap berikutnya yaitu pemanfaatan website untuk kegiatan-kegiatan lainnya di Karangantu. Website yang dibuat merupakan website e-commerse yang diberi nama Banten Bahari (BAHARI). Banten bahari merupakan sebuah sistem penjualan hasil laut dan olahan hasil laut secara online yang dibangun berbasis web dengan menggunakan framework Codeigniter 3 dalam bahasa pemrograman PHP. Penggunaan sistem ini, para nelayan dapat langsung memasarkan hasil lautnya secara online untuk meningkatkan hasil penjualannya. Hasil rancangan website Banten Bahari dapat dilihat pada gambar berikut.

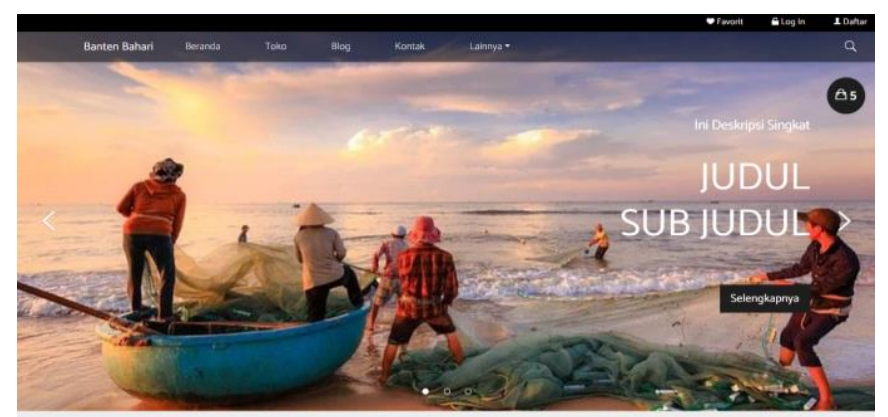

Gambar 4 Tampilan Awal Aplikasi

Terdapat 4 user dari website BAHARI yaitu pengunjung, pembeli, penjual dan admin. Pengunjung dapat dilayani oleh lebih dari satu penjual dengan menggunakan database yang sama, dan pihak yang bertugas (penjual dan admin) dapat memonitor sistem lewat jaringan yang sama, sehinga aliran informasi menjadi lebih efektif. Sistem BAHARI ini menggunakan antar muka berbasis web dan pengguna dapat menggunakan perangkat apapun yang terhubung ke internet menggunakan browser yang dimiliki.

Sistem BAHARI berjalan diatas hosting yang disediakan oleh pihak ketiga sehingga dapat diakses kapanpun asal terhubung melalui jaringan internet. Sistem BAHARI merupakan sistem yang terhubung ke jaringan internet sehingga pelanggan dapat dilayani oleh lebih dari satu penjual dengan menggunakan database yang sama. Pihak yang bertugas (penjual dan admin) dapat memonitor system lewat jaringan yang sama. Sistem yang dibuat menjadikan aliran informasi menjadi lebih lancar.

Aplikasi e-commerce banten bahari ini merupakan perangkat lunak yang digunakan untuk penjualan hasil laut berupa olahan baik makanan ataupun kerajinan. Aplikasi ECommerce sangat membantu pihak penjual dalam mendistribusikan barang dagangan (Apridiansyah dan Wijaya 2019). Sistem ini berkaitan dengan beberapa entitas luar, yaitu admin, penjual, pembeli/pelanggan/user hal-hal yang dilakukan oleh entitasentitas tersebut adalah:

1) User

Pengunjung: a) Dapat melihat produk yang dijual melalui web; b) Dapat menghubungi pihak penjual 
Konsumen: a) Dapat mengetahui produk yang dijual melalui web; b) Dapat menghubungi pihak penjual; c) Dapat membeli produk yang dijual di web Penjual: Dapat berdagang di etalase toko

2) Admin

Melakukan pengawasan terhadap seluruh sistem

Mengatur konfigurasi sistem.

Maintenance sistem.

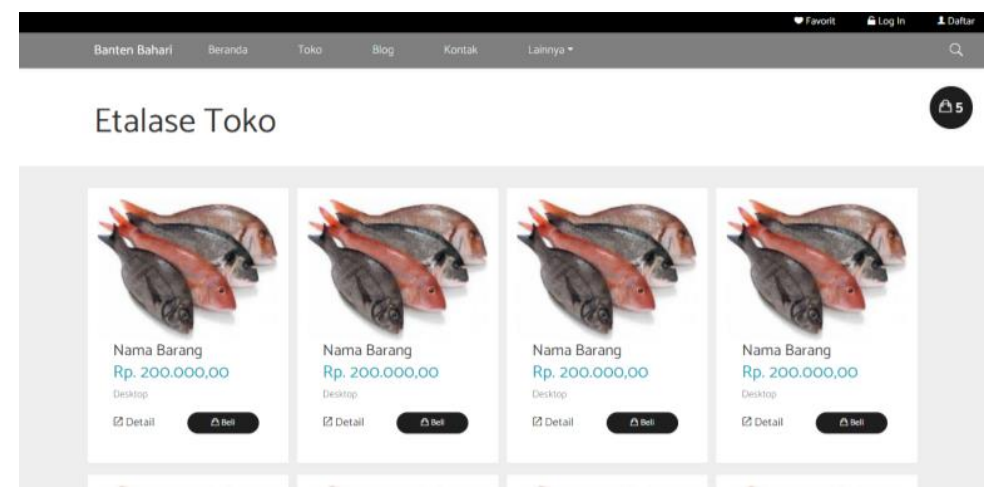

Gambar 5. Tampilan Etalase Toko

\section{SIMPULAN}

Sosialisasi pengenalan media online untuk pemasaran hasil laut di Karangantu di respons baik oleh istri-istri nelayan. Pembuatan website BAHARI merupakan salah satu media promosi yang dapat dimanfaatkan oleh istri-istri nelayan untuk kedepannya. Perlunya dilakukan pembinaan kelompok kecil pada pengenalan media promosi daring terlebih tentang website.

\section{Ucapan Terima Kasih}

Ucapan terimakasih ditujukan kepada LPPM UPI yang telah memberikan dukungan dan pendanaan, sehingga dapat terselanggaranya kegiatan pengabdian kepada masyarakat ini.

\section{REFERENSI}

Apridiansyah, Y., \& Wijaya, A. (2019). Aplikasi e-commerse hasil laut Bengkulu dengan penerapan algoritma SEO menggunakan ,odel sematik web. Jurnal Sistem Onformasi dan E-Bisnis, 1(5), 194-200.

BPS Kota Serang. (2019). Badan Pusat Statistik Kota Serang. Retrieved Februari 21, 2020 from https://serangkota.bps.go.id/

Chotijah, S. (2020). Literasi media sosial bagi millenials dalam mempromosikan pariwisata Lombok pasca gempa Agustus 2018. Jurnal Pengabdian Pada Masyarakat, 5(2), 596-602. https://doi.org/10.30653/002.202052.511. 
Hutagalung, S. S., Hermawan, D., \& Mulyana, N. (2020). Website desa sebagai media inovasi desa di Desa Bernung Kabupaten Pesawaran Provinsi Lampung. Jurnal Pengabdian Pada Masyarakat, 5(2), 299-308. https://doi.org/10.30653/002.202052.304.

Majdi, M. Z., Rizkiwati, B. Y., \& Wirasasmita, R. H. (2020). Penguatan nilai produk home industry menuju kesejahteraan masyarakat Desa Suradadi, Terara, Lombok Timur. Jurnal Pengabdian Pada Masyarakat, 5(2), 587-595. https://doi.org/10.30653/002.202052.526

Mansur \& Kasmawi. (2017). Pengembangan sistem database terpadu berbasis web untuk penyediaan layanan informasi website desa. Jurnal Nasional Teknologi dan Sistem Informasi, 3(1), 73-82. https://doi.org/10.25077/TEKNOSI.v3i1.2017.73-82.

Meliyawati., Rohimajaya, N. A., Purlilaiceu., \& Trisnawati. (2020). Pembelajaran digital sebagai media literasi di era revolusi industri 4.0. Jurnal Pengabdian Pada Masyarakat, 5(3), 639-645. https://doi.org/10.30653/002.202053.598

Mukhlis, M., \& Yulianto, Y. (2020). Transformasi kelompok wanita tani menjadi kelompok sadar wisata di Kecamatan Punggur Lampung Tengah. Jurnal Pengabdian Pada Masyarakat, 5(2), 319-334. https://doi.org/10.30653/002.202052.299.

Parsaorantua, P. H., Pasoreh, Y., \& Rondonuwu, S. A. (2017). Implementasi teknologi informasi dan komunikasi (Studi tentang web e-government di Kominfo Kota Manado). ACTA DIURNA KOMUNIKASI, 6(3), 114-127.

Santausa, I, T., Mustaruddin., \& Simbolon, D. (2020). Sistem basis data produksi ikan berbasis situs web (website) di Kabupaten Sukabumi-Jawa Barat. Jurnal Ilmu dan Teknologi Kelautan Tropis, 12(2), 473-485.

Tristianto, C. (2018). Penggunaan metode waterfall untuk pengembangan sistem monitoring dan evaluasi pembangunan pedesaan. Jurnal Teknologi Informasi ESIT, 12(1), 8-22.

\section{Copyright and License}

This is an open access article distributed under the terms of the Creative Commons Attribution 4.0 International License, which permits unrestricted use, distribution, and reproduction in any medium, provided the original work is properly cited.

(C) 2020 Novi Sofia Fitriasari, Ayang Armelita Rosalia, Luthfi Anzani, Della Ayu Lestari, Kukuh Widiyanto, Wildan Aprizal Arifin, Denta Tirtana, Fawaz, Cakra Rahardjo. 